\section{The Year 1991 in Review: Part II}

In last month's editorial I summarized the activities of Optical Engineering during 1991-Volume 30. I would like to conclude that discussion here.

\section{Growth of the Journal}

Figure 1 shows the number of technical pages published in Optical Engineering by issue for the past four years (Volumes 27 through 30 ). The percentage increases over each of these years have been $19.6 \%, 15.5 \%$, and $16.0 \%$, respectively. Our goal for 1992 is to reach 2,000 technical pages, thus continuing the trend. Figure 2 reviews the total number of technical pages published since 1978. Despite a steady overall rise, there have been some years of setback, for example, 1987 and 1988, and it is only the last two years that have shown gain over the 1986 figure. To clarify the term "technical pages," we have only counted those pages that are devoted to the technical papers. As readers will have noted, we have attempted to keep the number of pages not devoted to technical papers down to a reasonable minimum. However, we believe that these pages contain very valuable information including the table of contents, editorial schedule, editorials, book reviews, short courses and meetings calendars, information for contributors, and the annual indexes (in the December issue).

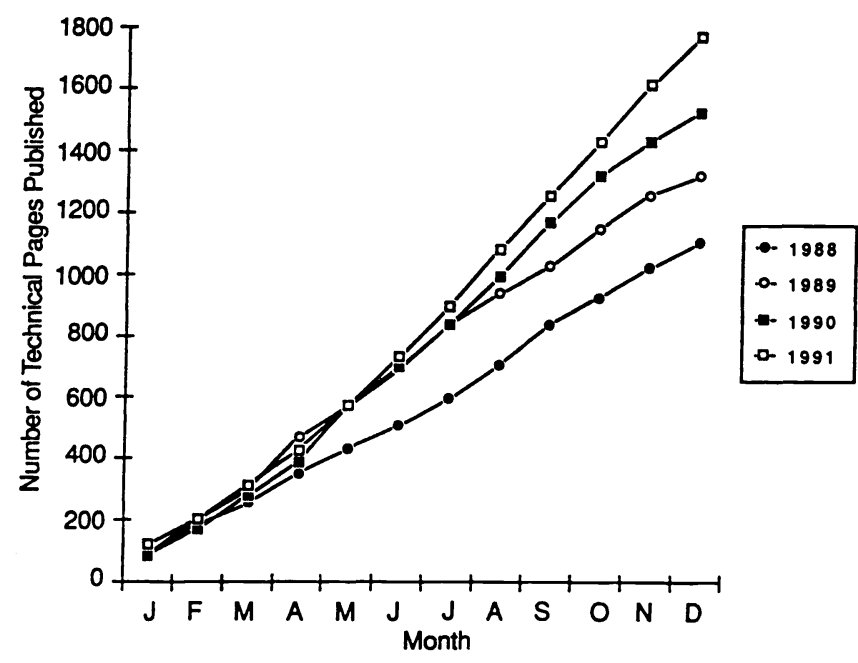

Fig. 1 The number of technical pages published by month from 1988 to 1991.

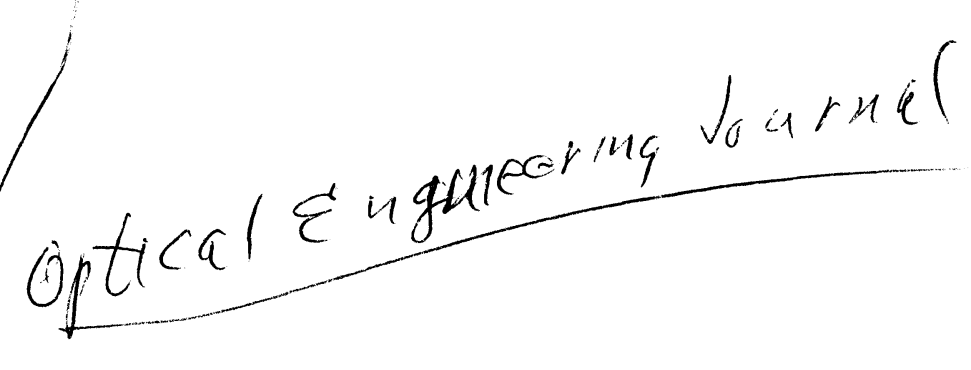

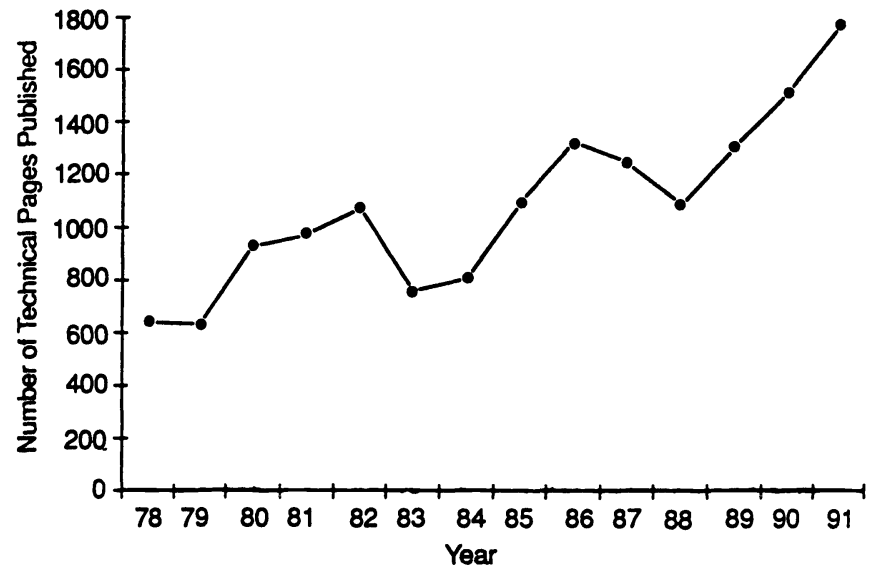

Fig. 2 The total number of technical pages published since 1978.

\section{Papers Received During 1991-Future Prospects}

The journal quality and its size are determined somewhat by the papers submitted and the special issues planned. Figure 3 shows the cumulative number of papers received each month for the last three years. This chart represents those papers that are submitted directly to me and, hence, the

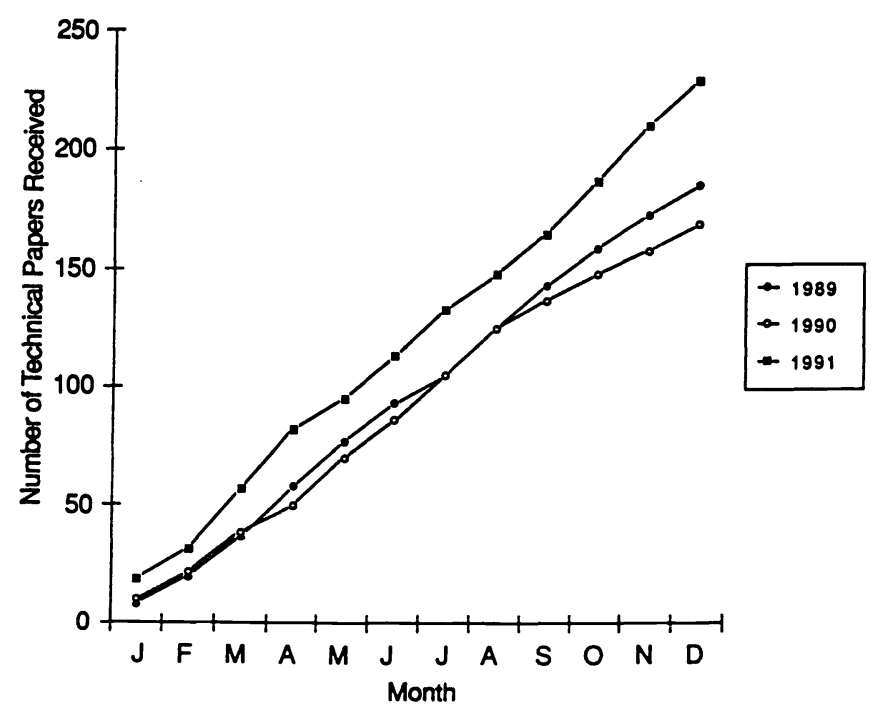

Fig. 3 The number of technical papers received by month from 1989 to 1991. 
numbers do not include the papers submitted for the special issues. The year 1991 started off strong and stayed strong through December. Many of the papers submitted during 1991 will appear in the journal during 1992.

A major effort has been under way to try to improve our procedures for handling papers and reduce the time to publication of those accepted. Quality cannot be sacrificed to meet these goals. However, we believe that significant progress has been made. For 1991 the average time from the day we receive a paper to the day my letter goes to the authors advising them of the results of the review process is 13 weeks; the median is 12 weeks. We hope that we can hold close to that time in the future. Obtaining qualified reviews in a timely manner would seem to be a challenge for most technical journals as evidenced by a recent editorial in the Journal of the Optical Society of America ${ }^{1}$ :

One continuing frustration was the inability to reduce the time delay in reaching editorial decisions. The median time for my office to respond to an author with an initial decision on a new submission remained almost constant at about 4 to $4-1 / 2$ months during the past 6 years. I sincerely hope that this delay will be reduced now that the manuscript office is centralized in Washington, but I am not optimistic. Providing a detailed review of a complicated theoretical paper is no mean task, and often the pool of qualified reviewers for some of the more arcane topics was very limited. We always insisted on two substantial reviews for every paper, and often they took many months to get.

I certainly understand his comment. Getting satisfactory reviews is more important than the time it takes to get those reviews.
The time authors take to revise their manuscripts is, of course, outside of our direct control. Once a revised manuscript is returned it is processed within a week and sent to the managing editor for publication-assuming that another review is not required. Currently, it takes an average of six months from the date a paper is accepted and sent to the managing editor until publication. We have a goal to reduce this time to five months. Incidentally, the median is also six months.

\section{Quality}

The quality and usefulness of the papers published are certainly more important than the timetable, but the higher the quality, the more useful the papers are and, hence, the more important timely publication becomes. My sense is that along with our improvement in publication time, we are also publishing even better papers.

\section{SPIE Member Contributions}

At the recent meeting of SPIE's Publications Committee in Los Angeles, I was asked about the number of members contributing papers. I was unsure of the answer at that time. I am pleased to report that $66 \%$ of the papers published during 1991 had at least one author who was listed as a member; $33 \%$ of all authors were listed as members.

\section{Sign Off}

So Volume 30 is really history-useful history. The purists among you who have read this far will probably find fault with my three figures. In particular, I perhaps more properly should have prepared them as histograms.

Page 648 of this issue takes us to the end of the first quarter with 547 technical pages, well on the way to our target.

Brian J. Thompson Editor 
April 1992

Optical Methods and Means of

Information Processing

Mikhail M. Miroshnikov

S.I. Vavilov State Optical Institute

199034, Birjevaya Liniya 12

Leningrad, USSR

May 1992

Optical Implementation of Information

Processing, Pattern Recognition, and

Neural Networks

Bahram Javidi

University of Connecticut

Department of Electrical and Systems Engineering

Room 312, U-157

260 Glenbrook Road

Storrs, CT 06269-3157

203/486-2867 • 203/486-0318 FAX

June 1992

Adaptive Signal Processing

Simon Haykin

McMaster University

Communications Research Laboratory

1280 Main Street West

Hamilton, Ontario L8S 4K1 Canada

416/525-9140

August 1992

Optical Engineering and U.K. Industry

Lionel R. Baker

Sira Led.

South Hill, Chislehurst

Kent BR7 5EH, United Kingdom

+44814672636• +4481467 6515 FAX

R. J. Parker

Rolls Royce plc

P.O. Box 31

Derby DE2 8BJ, United Kingdom

September 1992

Wavelet Transform

Harold H. Szu

U.S. Navy

Naval Surface Warfare Center, Code R44

10901 New Hampshire Ave.

Silver Spring, MD 20903-5000

301/394-3097 • 301/394-3923 FAX

October 1992

Acousto-Optics

Ting-Chung Poon

Virginia Polytechnic Institute and State University

Bradley Department of Electrical Engineering

Optical Image Processing Laboratory

Blacksburg, VA 24061

703/231-4876 - 703/231-3362 FAX

November 1992

Relay Mirror Experiment

Paul W. Kervin

USAF Phillips Laboratory

PLAMA (OL-YY)

P. O. Box 758

Puunene, HI 96784

808/871-7160 • 808/877-1231 FAX

Manuscripts due April 1, 1992.
December 1992

Automatic Target Recognition

Firooz Sadjadi

Systems and Research Center

Honeywell Inc.

3660 Technology Drive

Minneapolis, MN 55418

$612 / 782-7543 \cdot 612 / 782-7438$ FAX

Manuscripts due April 1, 1992.

January 1993

Optical Research in Asia

Chung J. Kuo

National Chung Cheng University

Department of Electrical Engineering

Chiayi, Taiwan 62107

886-5-272-0411, ext. 6210 • 886-5-272-0862 FAX unit151@twnmoe10.bitnet E-MAIl

Toshimitsu Asakura

Hokkaido University

Research Institute of Applied Electricity

Sapporo, 060 Japan

81-11-716-2111 • 81-11-758-3173 FAX

asakura@hikari.hokudai.ac.jp E-MAIl

Yong H. Lee

Korea Advanced Institute of Science

and Technology

Department of Physics

Yusung-Ku, Taejon, Korea

82-42-829-2536 - 82-42-861-1458 FAX

Run W. Wang

Shanghai Institute of Optics and Fine Mechanics

Academia Sinica

P.O. Box 800-211

Shanghai, 201800 China

February 1993*

Biomedical Optics

Abraham Katzir

Tel Aviv University

School of Physics

$69978 \mathrm{Tel}$ Aviv, Israel

011-972-3-421648 • 011-972-3-415850 FAX

*Note new issue date and manuscript deadline

Manuscripts due June 15, 1992.

March 1993

Optical Fiber Reliability II

Hakan H. Yuce

Belloore

445 South Street

Morristown, NJ 07962

201/829-4945 • 201/267-9753 FAX

Charles R. Kurkjian

AT\&T Bell Laboratories

600 Mountain Avenue

Murray Hill, NJ 07960-1910

908/582-2378 • 908/582-2783 FAX

Manuscripts due July 15, 1992.

\section{April 1993}

Emerging Optoelectronic Technologies

Vijai K. Tripathi

Oregon State Univeristy

Department of Electrical and Computer Engineering

Electrical and Computer Engineering

Building 220

Corvallis, Oregon 97331-3211

$503 / 737-3617 \cdot 503 / 737-1300 \mathrm{FAX}$

\section{May 1993}

Phase Contrast Microscopy

Maksymilian Pluta

Central Laboratory of Optics ul.

Kamionkowska 18

03805 Warszawa, Poland

48184405 or 48184497

Manuscripts due Oct. 1, 1992.

June 1993

From Numerical to Symbolic Image Processing: Systems \& Applications

G. Vernazza

Dipartimento di Ingegneria Biofisica ed Elettronica

Universita degli Studi di Genova

Via Opera Pia, 11a

16145 Genova, Italy

+39 10 353-2755 - +3910353-2777 FAX

This special issue will present innovative research and results on the integration between numerical and symbolic processing. Examples covering real applications will be considered. Manuscripts due Oct. 15, 1992.

July 1993

Visual Communication and Image

Processing IV

Kou-Hu Tzou

COMSAT Lab.

Image Processing Department

Room 1201

22300 Comsat Drive

Clarksburg, MD 20871

301/428-4663 - 301/428-7747 FAX

Manuscripts due Dec. 1, 1992.

September 1993

Optical Science and Engineering in Canada

C.P. Grover

National Research Council

Institute for National Measurement Standards

Ottawa, Canada K1 A OR6

613/993-2098 • 613/952-1394 FAX

Manuscripts due Feb. 1, 1993.

November 1993

Acquisition, Tracking, and Pointing

Mohammed A. Karim

University of Dayton

Center for Electro-Optics

300 College Park

Dayton, Ohio 45469-0227

$513 / 229-2241 \cdot 513 / 229-3433$ 